\title{
BIBLIOGRAFIA COMENTADA
}

En los últimos tiempos y en varias revistas han aparecido extensas bibliografías sobre el tema de la mujer. La mayor parte de ellas son traducciones de libros hechos en el exterior, aunque ya comienzan a aparecer cierta cantidad de estudios hechos en el país. Esta bibliografía no pretende ser extensiva a todo aquello que ha sido publicado sobre la mujer; ${ }^{1}$ en este caso sólo queremos citar los libros que nos parecen más generales y que creemos pueden ser mejor aprovechados por aquellos que quieran iniciarse en el tema del feminismo, ya sea por interés de investigación o por interés docente. La dividiremos en cuatro partes: Cuestiones teóricas sobre el feminismo; estudios especiales sobre el tema de la mujer; estudios sobre la realidad de la mujer en España y, por último, libros sobre la realidad de la mujer en otros países.

\section{CUESTIONES TEORICAS SOBRE EL FEMINISMO}

En términos teóricos hay distintas orientaciones y distintas corrientes que explican el origen de la opresión de la mujer. En general los podemos dividir en dos grandes corrientes, si bien dentro de ellas hay innumerables

1. Para una bibliografía completa ver El viejo topo, núm. 10, julio 1977. Bibliografía que aparece en el artículo «Dossier: Feminismo». 
diferencias. Una es lo que podemos llamar feminismo radical y la otra, feminismo socialista.

Dentro de la primera corriente dos son los textos fundamentales:

Firestone, Shulamith, La dialéctica del sexo (Barcelona: Ed. Kairos, 1976). Millet, Kate, Politica sexual (Madrid: Ed. Aguilar, 1977).

Dentro de la corriente socialista o marxista sobre la liberación de la mujer podemos a su vez hablar de los clásicos del marxismo y de las aportaciones más recientes. Los principales clásicos son:

Bebel, August, La mujer. En el pasado, en el presente, en el porvenir (Barcelona: Ed. Fontamara, 1975). Col. De la naturaleza de las cosas. Serie/Textos. Pr. Paul Lafargue, a la edición francesa de 1891. Engels, F., El origen de la familia, la propiedad privada y el Estado. En relación con las investigaciones de L. H. Morgan (Madrid: Ed. Ayuso, 1972).

En las aportaciones más recientes hay gtan cantidad de libros que han sido editados recientemente:

Abba, L.; Ferri, G; Lazzaretto, G.; Medi, E.; Motta, S., Conciencia de explotada (Valencia: Fernando Torres Ed., 1977).

Dalla Costa, María Rosa, Las mujeres y la subversión de la comunidad (México: Ed. Siglo XXI, 1975).

Rubio, Fini, ed., Marxismo y liberación de la mujer (Madrid: Dédalo Ediciones, 1977).

Finalmente, emergiendo dentro de la tradición marxista pero planteando un esquema más específicamente referido al problema de la mujer, tenemos dos textos. Uno es el clásico de Simone de Beauvoir, que a pesar de sus casi treinta años de existencia sigue siendo aún vigente. El otro es el de Juliet Mitchel:

Beauvoir, Simone, El segon sexe (Barcelona: Ed. 62, 1968). Dos vols. Prólogo de M. A. Capmany. (Edición castellana, Buenos Aires, Siglo XX.)

Mitchel, Juliet, La condición de la mujer (Barcelona: Editorial Anagrama).

2. ESTUDIOS ESPECIALES SOBRE EL TEMA DE LA MUJER

En este caso nos referimos a cuatro tipos de estudio sobre la mujer. 
En este caso estos estudios tienden a describir aquellos elementos culturales que se han mantenido a través del tiempo y la participación de la mujer en diversos movimientos sociales. Tenemos así en esta área tres libros que nos parecen interesantes:

Figes, Eva, Actitudes patriarcales (Madrid: Alianza Ed. Col. de bolsillo, núm. 396, 1972).

Oakley, Ann, La mujer discriminada. Biologia y sociedad (Madrid: Edit. Debate, Tribuna Feminista, 1977).

Rowsbotham, Sheila, Feminismo y Revolución (Madrid: Ed. Debate, 1977).

\section{Estudios psicológicos y sexuales}

Lo psicología y la sexualidad de la mujer eran dos temas que hasta época muy reciente parecían inamovibles y todos ellos producto de algo llamado la naturaleza de lo femenino. Más recientemente se ha intentado demostrar que la así llamada naturaleza femenina era en realidad producto de toda una tradición cultural. Recomendamos dentro de este área los siguientes libros:

Bardwick, Judith M., Psicologia de la mujer (Madrid: Alianza Editorial, 1976).

Castilla del Pino, Carlos, Cuatro ensayos sobre la mujer (Madrid: Alianza Ed., 1971).

Horney, Karen, Psicología femenina (Madrid: Alianza Ed., 1977. Col. Libros de Bolsillo, núm. 348).

Mitchell, Juliet, Psicoanálisis y feminismo (Barcelona: Ed. Anagrama, 1976).

\section{El trabajo de la mujer}

El trabajo de la mujer es otra de las áreas muy poco estudiadas y sobre la que existen gran cantidad de mitos. Esto tanto en lo que se refiere al trabajo doméstico, que es un trabajo que realizan todas las mujeres independientemente de si trabajan en el sector productivo o no y en cuanto a lo que se refiere al aporte de mano de obra femenina, ya sea en el transcurso del tiempo o en las sociedades actuales. 
Myrdal, A.; Klein, La mujer y la sociedad contemporánea (Barcelona: Ed. Península, 1967).

Varios, El ama de casa bajo el capitalismo (Barcelona: Ed. Anagrama, 1975).

Sullerot, Evelyne, Historia y sociologia del trabajo femenino (Barcelona:

Ediciones Península, 1970).

\section{Estudios sociológicos}

En este caso los tres libros que señalamos a continuación se refieren a mecanismos de la sociedad actual por medio de los cuales se diferencian los roles de lo masculino y lo femenino, vale decir los mecanismos por medio de los cuales la sociedad hace del ser mujer un hecho social. Como dice Simone de Beauvoir; «no se nace mujer, se llega a serlo».

Mattelart, Michèle, La cultura de la opresión femenina (México: Era, 1977). Rocheblave-Spenle, A. M., Lo masculino y lo femenino en la sociedad contemporánea (Madrid: Ed. Ciencia Nueva, 1968).

Sullerot, Evelyne, Mujer, sexo y sociedad industrial (Madrid: Ed. Cid, 1966).

\section{ESTUDIOS SOBRE LA REALIDAD DE LA MUJER EN ESPAÑA}

A partir de los años sesenta diversos estudios sobre la mujer en España han sido publicados. En los primeros tiempos correspondían al esfuerzo pionero de algunas feministas como María Aurelia Capmany y Lidia Falcón. Más recientemente y coincidiendo con el desarrollo del movimiento feminista estos estudios han comenzado a multiplicarse. Los que hemos seleccionado tienen relación con la mujer en el trabajo, la historia del desarrollo de las ideas feministas desde el siglo pasado, la represión y la mujer, la mujer en la guerra civil, la sexualidad femenina y el reciente desarrollo del movimiento feminista. Los libros que hemos seleccionado en esta sección son:

Alcalde, Carmen, La mujer en la guerra civil española (Madrid: Edit. Cam-

bio 16, 1976. Col. España Viva). Bibliografía. Pr. Lidia Falcón. Capmany, M. A.; Alcalde, Carmen, El feminismo ibérico (Barcelona: Ed. Oikos-Tau, 1970).

Capmany, M. A., La dona a Catalunya (Barcelona: Edicions 62, 1975). 
Comissió Catalana d'Ormentals. Secretariat de les Jornades, Jornades $\mathrm{Ca}$ talanes de la Dona (Barcelona: Ed. Alternativa, 1977).

Falcón, Lidia, En el infierno: ser mujer en las cárceles de España (Barcelona: Ediciones de Feminismo, 1977).

García Ferrando, Manuel, Mujer y sociedad rural. Un análisis sociológico sobre trabajo e ideología (Madrid: Ed. Cuadernos para el Diálogo, 1977. Bibliografía. Col. Divulgación Universitaria, Serie Sociología, núm. 108).

Moreno, Amparo, Mujeres en lucha (Barcelona: Ed. Anagrama, 1977).

Primeras Jornadas de Mujeres Trabajadoras (Madrid: Akal, 1977).

Scanlon, Geraldine M., La polémica feminista en la España contemporánea (1868-1974) (Madrid: Siglo XXI, 1976).

Serrano Vicens, Ramón, La sexualidad femenina. Una investigación estadística (Barcelona: Pulso Ed., 1971). Pr. Víctor Conill Serra.

Weiller, Martine, Mujeres activas: Sociología de la mujer trabajadora en España (Madrid: Ediciones de la Torre, 1977).

\section{LA REALIDAD DE LAS MUJERES EN OTROS PAISSES}

Desgraciadamente, han sido traducidos aún muy pocos libros que se refieran a la problemática de la mujer en otros países. Sin embargo, tanto en inglés como en francés hay gran cantidad de ellos. Quien se interese por el tema puede consultar con las distribuidoras feministas de Francia, Inglaterra y Estados Unidos.

Broyelle, Claudie, La mitad del cielo (México: Siglo XXI, 1976).

C. A. M. E., La mujer en la sociedad socialista (Madrid: Akal 74, 1976). Friedan, Betty, La mistica de la feminidad (Barcelona: Ed. Sagitario, 1965). Pierre, André, La m"jer en la Unión Soviética (Barcelona: Ariel, 1963). Randall, Margaret, Mujeres en la revolución (México: Siglo XXI, 1972). Randall, Margaret, El espíritu de un pueblo (México: Siglo XXI, 1975). Tillion, Germaine, La condición de la mujer en el área mediterránea (Barcelona: Ediciones Península, 1967). 